\title{
SIGNIFICADO DE TER INCONTINÊNCIA URINÁRIA E SER INCONTINENTE NA VISÃO DAS MULHERES ${ }^{1}$ THE MEANING OF URINARY INCONTINENCE AND BE INCONTINENT - WOMEN OPINION EL SIGNIFICADO DE TENER INCONTINENCIA URINARIA Y SER INCONTINENTE EN LA VISIÓN DE LAS MUJERES
}

\author{
Alessandra Maria Cotrim de Borbaํ, Maria Alice dos Santos Lelis ${ }^{3}$, Ana Cristina Passarella Brêtas ${ }^{4}$
}

\footnotetext{
${ }^{1}$ Recorte da dissertação de mestrado defendida no Programa de Pós-Graduação em Enfermagem da Universidade Federal de São Paulo (UNIFESP) em 2007.

${ }^{2}$ Mestre em Enfermagem. Professora da Universidade Cidade de São Paulo. São Paulo, Brasil.

${ }^{3}$ Doutora em Ciências da Saúde. Professor Adjunto do Curso de Enfermagem da Irmandade da Santa Casa de Misericórdia São Paulo. Co-orientadora. São Paulo, Brasil.

${ }^{4}$ Doutora em Enfermagem. Professor Adjunto do Departamento de Enfermagem da UNIFESP. Orientadora da dissertação. São Paulo, Brasil.
}

PALAVRAS-CHAVE: Incontinência urinária. Emoções. Cuidados de enfermagem. Saúde da mulher. Pesquisa qualitativa.
RESUMO: O objetivo deste estudo qualitativo foi compreender as repercussões da incontinência urinária na vida de mulheres e conhecer o significado das crenças, valores e atitudes de TER incontinência e SER incontinente. O método utilizado foi a história oral temática e a coleta de dados ocorreu de agosto a outubro de 2005 em dois momentos distintos. Inicialmente com a aplicação de instrumentos específicos para incontinência urinária e posteriormente foram coletados os dados subjetivos por meio de entrevistas com questões semi-estruturadas. Utilizando a análise temática, encontramos quatro unidades centrais - percebendo que a perda não é normal, tendo sentimentos diante da perda, tendo que assumir a incontinência urinária, tendo que ter controle para não perder ou cheirar urina. Identificamos, pela análise das unidades, a apreensão do fenômeno SER incontinente compreendendo que as mulheres possuem estratégias individuais para lidarem com a relação dialética entre o SER e o TER incontinência urinária.

KEYWORDS: Urinary incontinence. Emotions. Nursing care. Women's health. Qualitative research.

PALABRAS CLAVE: Incontinencia urinaria. Emociones. Atención de enfermería. Salud de la mujer. Investigación cualitativa.

ABSTRACT: The objective of this qualitative research was to better understand the repercussions of urinary incontinence in women's lives and to learn the meaning of the beliefs, values, and attitudes of HAVING incontinence and BEING an incontinent person. The method utilized was the thematic oral history and data was collected from August to October of 2005 in two different periods. First, we applied specific instruments for urinary incontinence. Afterwards, subjective data was collected using interviews with semi-structured questions. Through thematic analysis, four thematic fields were found - realizing that loss is not normal, having feelings in facing the loss, having to accept urinary incontinence, and having to have control not to lose or smell urine. We concluded, using unitary analysis, the apprehension of the phenomenon of BEING incontinent, understanding that women have individual strategies for dealing with the dialectic relationship between HAVING urinary incontinence and BEING an incontinent.

RESUMEN: El objetivo de este estudio cualitativo fue comprender las repercusiones de la incontinencia urinaria en la vida de las mujeres y conocer el significado de las creencias, valores y actitudes de TENER incontinencia y SER incontinente. El método utilizado para el análisis fue la historia oral temática. Los datos fueron recolectados en los meses de agosto a octubre de 2005, en dos momentos distintos. En un primer momento, se emplearon instrumentos específicos para la incontinencia urinaria, y en un segundo momento, se recolectaron los datos subjetivos por medio de entrevistas con preguntas parcialmente elaboradas. En el análisis surgieron cuatro temas centrales - dándose cuenta de que la pérdida no es normal, teniendo sentimientos relacionados con la pérdida, obligadas a asumir la incontinencia, la necesidad de tener control para no perder u oler a orina. Por medio del análisis de las unidades, pudimos concluir que las mujeres poseen estrategias individuales para lidiar con la relación dialéctica entre el SER incontinente y TENER incontinencia urinaria.
Alessandra Maria Cotrim de Borba

Endereço: Lavínia Fenton, 30

04663-170 - Jardim Marajoara, São Paulo, SP, Brasil

E-mail: alecotrim@netpoint.com.br
Artigo original: Pesquisa Recebido em: 15 de janeiro de 2008 Aprovação final: 22 de agosto de 2008 


\section{INTRODUÇ̃̃O}

A Incontinência Urinária (IU) é uma condição angustiante e incapacitante, causando morbidade, afetando a vida nos aspectos social, psicológico, ocupacional, doméstico, físico e sexual de 15 a 30 $\%$ de mulheres em todas as idades. ${ }^{1}$ A IU é um significante problema de saúde com dimensões mundiais, dado ao impacto social e econômico que causa na vida dos indivíduos e reflete na relação que têm na sociedade. $^{2}$

A IU, de acordo com os sintomas, pode ser classificada em três tipos principais: a incontinência urinária de esforço, quando ocorre perda involuntária de urina durante o esforço ou exercício ou ao espirrar ou tossir; a urge-incontinência, caracterizada pela queixa de perda involuntária de urina acompanhada ou imediatamente precedida por urgência e a incontinência urinária mista, quando há queixa de perda involuntária de urina associada à urgência e também aos esforços, exercício, espirro ou tosse. ${ }^{3}$

Quanto ao tipo de incontinência podemos encontrar índices de $42 \%$ de incontinência urinária mista, 38\% de incontinência de esforço e 18\% de urge-incontinência. ${ }^{4}$ Outros valores similares foram encontrados em mulheres chilenas que possuíam $46,1 \%$ IU mista, 40,7\% com IU de esforço e $13,2 \%$ com urge-incontinência. ${ }^{5}$

No Brasil são poucas as descrições quanto à prevalência da IU na população brasileira. Esses valores são descritos de acordo com o tipo de IU sendo restritos os estudos por inquérito populacional. Observou-se em mulheres climatéricas que $35 \%$ delas apresentavam queixa de incontinência urinária de esforço. ${ }^{6}$ Em outro estudo, com profissionais de enfermagem, a prevalência do sintoma de perda urinária foi de $27,5 \%$ na população estudada, com maior ocorrência da IU mista $(33,8 \%)$, seguida pela de esforço $(27,5 \%)$ e pela urge-incontinência $(20 \%){ }^{7}$

Nos adultos e idosos hospitalizados em um hospital escola localizado no município de São Paulo identificou uma prevalência total de $35 \%$ de incontinência urinária e parciais de $48 \%$, $37 \%$ e $22 \%$ respectivamente nas clínicas cirúrgica, obstétrica e médica. ${ }^{8}$ A IU possui uma prevalência considerável tanto no Brasil quanto no exterior, merecendo destaque entre as pesquisas científicas. O crescente número de mulheres em processo de envelhecimento torna necessário o desenvolvimento de estudos que abordem as mais diversas facetas da IU.
As conseqüências que a IU pode gerar no indivíduo atingem uma ampla esfera que envolve trauma psicológico, ansiedade e sentimentos como solidão, culpa e humilhação; além de restrições no convívio social e sexual. ${ }^{9}$ A vivência com a IU leva a mulher realizar os mais diversos mecanismos de modificações comportamentais para se adaptar as inconveniências da perda urinária como: uso freqüente de perfumes de odor forte; utilização de roupas escuras; diminuição da ingesta hídrica; suspensão por conta própria de fármacos que estimulem a eliminação urinária; uso de absorventes ou protetores para controle da perda urinária; procura imediata pelo banheiro em locais públicos, além de evitarem o convívio social.

Apesar de a IU ocasionar alterações na vida das pessoas que a vivenciam, um grande número de mulheres com queixa de IU persistente leva um longo período para procurar assistência adequada, fato que pode ser explicado devido a fatores culturais, familiares ou ainda pelo constrangimento, aliado ao desconhecimento de possibilidade terapêutica. ${ }^{10}$ Tais achados propiciam o questionamento que a busca pelo tratamento pode ser influenciada pelas crenças e valores que as mulheres possuem acerca do que é ser incontinente.

Assim, os objetivos do estudo são de conhecer o significado das crenças, valores e atitudes de mulheres sobre ser incontinente e ter incontinência urinária e; avaliar as repercussões da incontinência urinária na vida de mulheres com queixas de perdas urinárias.

\section{MÉTODO}

\section{Tipo de estudo}

Este estudo qualitativo foi construído por meio do método da História Oral Temática, que se relaciona a padrões culturais, estruturas sociais e processos históricos individuais capazes de dar corpo ao imaginário coletivo, buscando a sua essência nas conversas sobre a memória dos que viveram e o impacto que essas experiências tiveram em suas vidas. ${ }^{11-12}$

\section{Local do estudo}

Realizado em um ambulatório de Enfermagem em Uroneurologia e Urologia Feminina de um hospital público de grande porte na cidade de 
São Paulo. Foi aprovado pelo Comitê de Ética em Pesquisa da Universidade Federal de São Paulo, protocolo $\mathrm{N}^{\circ} 169 / 2005$.

\section{Sujeitos do estudo}

Participaram do estudo seis mulheres escolhidas por apresentarem queixas de perdas urinárias de pelo menos uma vez por semana nos últimos três meses, por estarem em condições físicas e mentais de serem entrevistadas e por concordarem em participar da pesquisa assinando o Termo de Consentimento Livre e Esclarecido. Para a seleção não consideramos o diagnóstico médico sobre o tipo de IU apresentada e sim os relatos das perdas urinárias independentemente da classificação do tipo de incontinência.

\section{Coleta de dados}

Os dados foram coletados no período de agosto a outubro de 2005, em dois momentos distintos com um intervalo entre eles inferior a 30 dias. No primeiro, realizamos a caracterização demográfica, sócio-econômica e das condições de saúde utilizando instrumentos com questões fechadas específicos para IU recomendados pela Internacional Consultation Society. No segundo, coletamos os dados qualitativos por meio da técnica da entrevista, utilizando um instrumento com questões semi-estruturadas que abordaram questões relativas à experiência da perda urinária. As entrevistas foram gravadas, catalogadas e transcritas pela pesquisadora visando assegurar o sigilo acordado com as depoentes. Elas duraram entre 60 a 90 minutos de gravação. Utilizamos nomes de cidades italianas para identificar as narradoras e assim garantir o anonimato acordado com elas.

A necessidade de obter dados quantitativos visou uma primeira aproximação com as narradoras para identificar questões relacionadas ao fato de terem perda urinária e com isso, preparar o cenário e construir um instrumento com questões semiestruturadas para operacionalizar as entrevistas.

\section{Análise dos dados}

As informações que foram subtraídas no primeiro contato permitiram a identificação da objetividade de TER incontinência. Enquanto que as narrativas, extraídas no segundo encontro, possibilitaram a interpretação de dados subjetivos sobre o sentimento de SER incontinente para cada mulher. Optando por esse tipo de análise, junção dos dados objetivos aos subjetivos, pudemos ampliar a visão sobre a temática da IU. Para operacionalizar a análise seguimos as seguintes etapas: ordenação e classificação dos dados obtidos nos textos (empíricos e teóricos), buscando relacionar as categorias analíticas (teóricas) e as empíricas; realização de análise crítica relacional entre os dados classificados e as categorias selecionadas dos campos temáticos.

\section{RESULTADOS}

Os resultados da junção dos dados objetivos com os subjetivos nos permitiram identificar a maneira de abordar as mulheres com perdas urinárias. A relação da subjetividade com a objetividade dos dados, mostrou a relação sentimento e razão.

Na Figura 1 apresentamos esquematicamente a relação dialógica por nós trabalhada entre o SER incontinente e o TER incontinência.

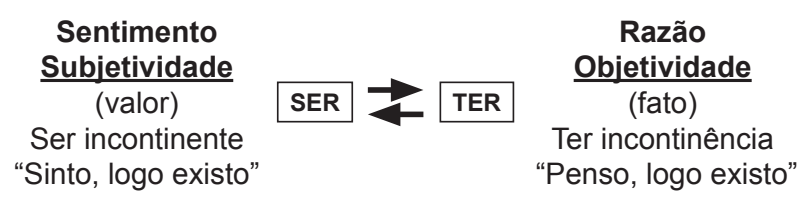

Figura 1 - Relação da subjetividade com a objetividade dos dados: sentimento e razão

As mulheres apreenderam a IU no momento em que objetivaram a doença e conferiram o valor ao adoecimento. As seis mulheres entrevistadas estavam inseridas na faixa etária de 39 e 73 anos; três eram casadas, uma viúva, uma separada e a outra solteira. Cinco referiram ser brancas e uma negra. Quanto ao grau de escolaridade, três possuem o ensino fundamental completo, uma incompleto e as outras duas realizaram o ensino médio, sendo que uma completou e a outra não. No Quadro 1 apresentamos as informações sobre o TER incontinência, aproveitando para caracterizar os sujeitos do estudo.

O acompanhamento ginecológico era realizado por cinco mulheres, sendo que apenas duas destas afirmavam manter atividade sexual, quatro estavam na menopausa, porém três relataram os sintomas. A terapia de reposição hormonal era realizada por apenas uma destas mulheres. 
Quadro 1 - Dados de avaliação da infecção urinária das mulheres com perda urinária. São Paulo SP, 2007.

\begin{tabular}{|c|c|c|c|c|c|c|}
\hline Categorias & & & Suj & itos & & \\
\hline & Roma & Veneza & Verona & Milão & Cotorna & Amalfi \\
\hline Diagnóstico médico & IU esforço & IU esforço & IU esforço & $\begin{array}{c}\text { Urge- } \\
\text { incontinência }\end{array}$ & $\begin{array}{l}\text { Urge- } \\
\text { incontinência }\end{array}$ & IU mista \\
\hline Tempo de queixa & 1 a 3 anos & 3 a 5 anos & $>5$ anos & $>5$ anos & $>5$ anos & 3 a 5 anos \\
\hline $\begin{array}{l}\text { Tempo para procurar } \\
\text { atendimento }\end{array}$ & 1 a 3 anos & 1 a 3 anos & $<1$ ano & $>5$ anos & $>5$ anos & 1 a 3 anos \\
\hline Tratamento anterior para IU & Não & Não & Sim & Sim & Sim & Não \\
\hline Tipo de queixa & IU de esforço & IU de esforço & IU mista & IU mista & IU mista & IU mista \\
\hline Noctúria & Sim & Não & Sim & Sim & Sim & Sim \\
\hline Frequência & $\begin{array}{c}1 \mathrm{a} 2 \\
\text { vezes/noite }\end{array}$ & - & $\begin{array}{c}1 \text { a } 2 \\
\text { vezes/noite }\end{array}$ & $\begin{array}{c}1 \text { a } 2 \\
\text { vezes/noite }\end{array}$ & $\begin{array}{c}3 \text { a } 4 \\
\text { vezes/noite }\end{array}$ & $\begin{array}{c}1 \text { a } 2 \\
\text { vezes/noite }\end{array}$ \\
\hline $\begin{array}{l}\text { Proteção } \\
\text { para perdas }\end{array}$ & Sim & Sim & Sim & Não & Sim & Sim \\
\hline Tipo de proteção & Absorvente & Absorvente & Absorvente & - & Toalhinha & Absorvente \\
\hline Número de protetores/dia & 1 a 2 & 1 a 2 & 1 a 2 & - & 1 a 2 & 3 a 4 \\
\hline
\end{tabular}

Quanto ao quadro obstétrico, cinco mulheres referiram gestações anteriores variando de uma a três gestações; uma relatou 14 gestações. Quatro mulheres tiveram parto normal, uma foi submetida ao parto cesárea e a outra teve tanto parto normal quanto cesariana.

Os resultados dos dados subjetivos foram construídos valendo-se do conteúdo obtido nas narrativas. Deste processo de análise emergiram quatro unidades temáticas: percebendo que a perda não é normal, sentimentos diante da perda urinária, tendo que assumir a incontinência urinária e ter controle para não perder e/ou cheirar urina.

\section{DISCUSSÃO}

A junção da relação entre o TER incontinência e SER incontinente, permitiu a compreensão da relação dialógica entre o SER e TER, uma vez que amplia a compreensão da totalidade da mulher que perde urina, permitindo desta forma uma assistência de enfermagem humanizada. A experiência-base da vida humana é o sentimento, o afeto, o cuidado e não apenas o cogito cartesiano. A razão não explica tudo nem abarca tudo; da mesma forma que o sentimento não expressa a totalidade do ser. Razão e sentimento precisam andar juntos, redescobrir que são dimensões do mesmo corpoportanto inseparáveis. Desta combinação nasce o cuidado - a essência concreta do ser humano. ${ }^{13}$
A análise dos resultados indicou que as mulheres deste estudo estão na faixa etária encontrada na literatura. ${ }^{14-15} \mathrm{~A}$ idade das depoentes foi semelhante à de outras mulheres em trabalhos nacionais. ${ }^{6}$ Em outro estudo, $60,78 \%$ das mulheres estavam com 45 a 60 anos, 31,38\% possuíam idade inferior a 45 anos e 7,84\% com mais de 60 anos. ${ }^{16}$ Esses achados contribuem para desmistificar que a IU acomete apenas, ou principalmente, idosas.

$\mathrm{Na}$ avaliação da IU, o diagnóstico médico quanto ao tipo de IU diverge de acordo com a população estudada. Em um estudo desenvolvido na Europa, 35\% da população apresentou perda urinária nos últimos 30 dias, sendo a incontinência de esforço ou estresse o tipo mais prevalente. Os parâmetros foram os seguintes: $37 \%$ de incontinência por estresse, 20\% de urge-incontinência, 33\% de incontinência mista e $10 \%$ de outros tipos de IU. ${ }^{15}$ Houve proximidade em outra população, na qual $40,7 \%$ foram de incontinência por esforço, $46,1 \%$ incontinência mista e 13,2\% urge-incontinência. ${ }^{5}$ Valores similares foram encontrados numa pesquisa brasileira, 33,8\% manifestaram sintomas de incontinência mista, 27,5\% de incontinência de esforço, $20,0 \%$ de urge-incontinência, $16,2 \%$ de outros tipos de incontinência urinária e 2,5\% não respondeu. ${ }^{7}$

A noctúria foi referida pelas depoentes, suas principais causas são: a diminuição da capacidade vesical e/ou o aumento na produção de urina 
no período noturno, podendo estar associada a outros sintomas do trato urinário inferior, especificamente a IU. ${ }^{17}$ É o terceiro sintoma mais comum da incontinência e, uma pesquisa mostra que, $63 \%$ da população britânica estudada, considera um problema importante. ${ }^{18}$

A utilização de recursos para a contenção da perda urinária é uma prática comum adotada pelas mulheres nessa condição. $\mathrm{O}$ absorvente e a toalhinha de pano são os métodos mais empregados. Cinco mulheres manejavam a perda de urina com absorvente e toalhinha substituindo-o de uma a duas vezes/dia, e uma não utilizava nenhum recurso. Um estudo confirmou que $62,74 \%$ das mulheres utilizavam recursos para a contenção, das quais 50,98\% com freqüência de duas ou mais trocas ao dia. ${ }^{16}$

$\mathrm{Na}$ análise dos dados subjetivos, a mulher começa a ter contato com o seu SER incontinente quando ela percebe que a perda urinária não é uma condição natural. Neste momento, emerge a unidade temática - Percebendo que a perda não é normal.

Desde a antiguidade o ser humano procura maneiras de lidar com os seus excrementos, as substâncias eliminadas do seu corpo, uma vez que essas são consideradas escórias, produzidas pelo nosso organismo, devendo ser abolidas. A maneira precisa e adequada para que isso ocorra é o controle do esfíncter, propiciando a eliminação privativa em local e hora apropriada, sem que haja o manuseio com as excretas. A partir do momento que passamos a controlar o nosso esfíncter, essa condição é incorporada como um padrão de normalidade. Algo que se distancie dessa condição torna-se um sinal de alerta.

Na condição da perda urinária, a mulher deixa de cumprir a norma da continência. Com isso: "o ser vivo doente está normalizado em condições bem definidas, e perdeu a capacidade normativa, a capacidade de instituir normas diferentes em condições diferentes" . ${ }^{19: 146}$ Neste momento ela percebe que a sua função de controlar a urina pode estar comprometida.

Ah, se eu estou, por exemplo, é conversando numa turma se eu der muita risada, aquilo lá, como já acontece de sair o xixi, não é normal [...]. Você sabe que isso não é normal, numa pessoa normal não acontece. Normal é você não perder, perder só na hora exata de fazer o xixi [...] (Roma).

Eu acho que é anormal, normal não é porque as pessoas que eu converso tudo, não têm esse problema e eu tenho. Ah! normal seria assim se não tivesse esse problema, não tivesse nada se fosse tudo normal, nem vazamento da bexiga, nem com aquela vontade louca de urinar e nem ficar perdendo (Amalfi).

A percepção da perda da normalidade no controle da eliminação urinária, em situação indesejada, é identificada pela dificuldade de conter a urina armazenada, muitas vezes reconhecida por meio de um sinal de urina na calcinha. Sinal é o que serve de advertência, ou possibilita conhecer ou prever algo. Então, a mulher passa a observar a sua eliminação urinária em busca de outras características que sugerem anormalidades.

O controle da urina é dito "normal", ou seja, a continência, quando a pessoa possui a capacidade normal de acumular urina, com controle consciente sobre o tempo e lugar para urinar. O padrão de normalidade de cada indivíduo, quanto à eliminação urinária está pautada diante da sua experiência de funcionamento do seu próprio organismo.

O lidar constante ou esporádico com a perda urinária permite a mulher vivenciar um turbilhão de emoções e sentimentos. O contato com a IU desencadeou a interpretação da segunda unidade temática - Sentimentos diante da perda urinária.

Os sentimentos vivenciados por essas mulheres geralmente estão contextualizados na esfera física ou moral, não são emoções ou alegrias. As mulheres normalmente descrevem sentir constrangimento, vergonha, humilhação e desgosto associado à incontinência, ${ }^{20}$ bem como nervosismo, medo, perda da confiança em si e tristeza.

Nas narrativas, verificamos sentimentos, como os apresentados por esse trecho, que permeiam a vida da mulher com IU e o impacto que representa sobre a sua vida social e o seu bem-estar.

Fiquei com vergonha, a gente fica meio sem jeito, ficam pensando, nossa aquela senhora mijando na roupa, mijando nas calças, mas não é porque você quer, é uma coisa que acontece, você tá às vezes dentro do ônibus e os balanços do ônibus e os pulos que dá, depende do carro, sai mesmo (Amalfi).

A vergonha está relacionada à moralidade, na qual o envergonhado estabelece uma relação entre o juízo próprio e o juízo alheio. O problema essencial do sentimento de vergonha é o juízo alheio, desencadeado pela opinião de outrem e que, portanto, ele pertence ao domínio público exercendo um controle externo. ${ }^{21}$

A preocupação é notória na narrativa de Amalfi. Ela narra a preocupação com o juízo alheio manifestado por meio da vergonha, assim trazendo a ótica da estigmatização da mulher incontinente 
pelo coletivo. O receio de vivenciar a vergonha em público é tão intenso, que o juízo alheio cobra medidas preventivas para evitar a perda urinária.

Ah porque às vezes a pessoa pensa assim nossa essa mulher sai, não sabe se prevenir ou usar um modess para não ficar aparecendo esse xixi na roupa. Porque é uma coisa que dá vergonha, não é [...] nossa que mulher mijona. Já vi muito isso aí, dá vergonha. Vocêfica com vergonha, não sei (Amalfi).

O controle das eliminações é construído socialmente, assim como os estigmas em torno da IU. Nas sociedades atuais existem fortes normas culturais quanto ao manejo das eliminações, pois são associadas a algo nojento e que provoca doenças. Estes valores são internalizados ao longo da vida, e quando alguns adultos não conseguem cumpri-los, são estigmatizados.

Entre as restrições causadas pela IU foram identificadas, em estudo nacional, que 26,2\% das mulheres, citaram problemas psicológicos e emocionais associados à IU como vergonha, medo, nervosismo e depressão. Mulheres com incontinência mista relatavam fazer tratamento para depressão (5,3\%), ter medo de perder urina durante a relação sexual $(4,2 \%)$, sentir constrangimento e tristeza por causa da IU $(2,1 \%)$, ter vergonha do marido ao perder urina durante o ato sexual $(3,8 \%)$, enquanto que as mulheres com urge-incontinência referiam ficar chateadas, nervosas e incomodadas com a IU $(6,2 \%) .{ }^{22}$

Em um estudo com trabalhadoras da área de enfermagem, a queixa principal $(10,6 \%)$ foi o estresse por ficar molhada, cheirando urina e não podendo interromper o trabalho, ou porque interrompiam o trabalho para irem ao banheiro. Outros sentimentos, citados por $13,4 \%$ foram vergonha, raiva, constrangimento e preocupação por ficar molhada ou estar cheirando urina. ${ }^{7}$

O manejo do TER IU faz com que a mulher vivencie um turbilhão constante de sentimentos, muitas vezes negativos, que podem levá-las a quadros de tristeza e depressão.

Então é a gente fica, porque dá um pouquinho de depressão porque, Deus me livre de depressão, [...] você fica triste, você fica solitária, então você o que quer que venha na sua cabeça depressão, ah então pra mim num ficar chateada a gente aprende a falar, eu tô um pouco deprimida, é esgotada. [...] Então, mexe muito psicologicamente, [...] Então, aí é tipo isso mexe, mexe muito com a gente (Roma).

Olha quando eu vim pra cá eu estava mal, psicologicamente muito mal [...]. Afeta bastante porque a gente de hora em hora tem que ir ao banheiro e é muito ruim, é triste a gente fica triste [...] eu já sofri que nem cachorro com esse problema de infecção urinária, já sofri muito mesmo. [...] Perder a urina foi bem trágico (Milão).

A depressão e a ansiedade têm sido sugeridas como uma ocorrência usual nas pessoas com IU, porém não está clara a relação entre elas. Há uma importante associação entre a incontinência e os sintomas de ansiedade e de depressão; e o quadro clínico pode piorar conforme o grau de perda. ${ }^{23-25}$

A partir do momento que a mulher percebe que a perda urinária não é normal e que consegue rever os seus sentimentos diante desse impasse, ela posiciona-se. Para poder manter a sua vida com o mínimo de alteração, acredita que deve assumir o seu TER incontinência urinária. Neste momento emerge a unidade temática - Tendo que assumir a incontinência urinária e ter controle para não perder e/ou cheirar urina. A mulher passa a tomar decisões claras e objetivas diante do problema detectado.

Uma característica interessante dessa unidade é que, não necessariamente, ela irá assumir a condição de TER incontinência publicamente, mesmo porque há o receio do estigma, assim ela tomará para si a responsabilidade de gerenciar esse evento. Durante este período pode ocorrer acomodação ou adaptação dessa mulher, o que a permite ser mais tolerante como as perdas urinárias. ${ }^{20}$

As mulheres ao assumirem a IU podem se sentir mais seguras, confiantes e tomam a iniciativa de dividir o evento com alguém.

Então, eu acho que a gente tem que se assumir, por que não adianta ficar escondendo [...] acho que se você esconde um problema é pior, vocêfica se remoendo assim por dentro, escondendo num lugar que ninguém fica sabendo por dentro, eu acho pior (Veneza).

Diante deste cenário, a decisão de assumir a perda urinária depende, a maior parte, da própria mulher, porquê ela pode apropriar-se do TER incontinência e, mais dificilmente, do SER incontinente.

Esta unidade temática fecha o ciclo do SER incontinente, estabelecendo com as demais um fluxo contínuo de interligação para equilibrar a condição de TER incontinência na vida. Nesta unidade, as mulheres estabelecem uma relação intensa e contínua com o TER incontinência. Elas realizam manobras de contenção na tentativa de manter a normalidade de sua vida. Essa condição exige da mulher um controle e vigilância contí- 
nua, pois o seu maior receio é vivenciar o TER publicamente, confirmando diante de uma platéia o SER incontinente.

A busca pelo controle leva a uma luta constante com o próprio corpo e lhes impõem regras rígidas para que não percam urina. As restrições freqüentes sempre levam as mulheres a pensar no TER incontinência. A presença do controle as mantém em alerta e isso faz com que não consigam se desvencilhar da sua condição de TER.

[...] tem que ter muito controle. Você fica chateada porque tem que prender porque senão vai escorrer, e é pior pra você. Tá indo ao banheiro, não ficar com a bexiga muito cheia, ir ao banheiro para não dar nenhum vexame, por exemplo, pra não acontecer acidente de vai lá [...], eu me protejo [...]. Eu só tenho o cuidado, tem que ficar atenta (Roma).

É, eu já tive situação bem, bem difícil. Já afetou muito, hoje eu tô aprendendo a controlar, sabe, a controlar mais essa vontade de ir mais vezes ao banheiro, porque você fica sempre com a bexiga vazia, pra não acontecer de espirrar e já soltar quase tudo. Eu controlo indo ao banheiro (Milão).

As mulheres percebem que deixam de ter o controle da sua vida e buscam restabelecê-lo tentando retomar a normalidade por meio da consciência das alterações que a perda urinária ocasiona. O restabelecimento do controle engloba estratégias de enfrentamento para conviver e administrar as perdas urinárias. ${ }^{26}$ Muitas vezes, é um longo caminho, cheio de vivências e de experiências, mas ela tem que lutar. Nesta batalha a mulher precisa retomar o controle sobre o TER perda urinária para não viver em função da doença e para não ser controlada por ela. Na busca pelo autocontrole, as mulheres fazem o quê consideram que precisa ser feito para ter um estilo de vida normal. ${ }^{27}$

Faço qualquer coisa pra eu num ter que ficar com a bexiga cheia, pra eu não ter que perder (Roma).

A expressão utilizada por Roma demonstra uma das estratégias utilizadas para ter o controle, a maioria das mulheres utiliza mecanismos de contenção como o uso de absorventes, utilização freqüente de banheiros e restrição hídrica. Diante da possibilidade eminente de perder urina, as mulheres abrem mão dos seus princípios e valores se sujeitando a qualquer condição para manter-se no controle.

[...] se eu tiver com vontade e tiver perto de um bar, não quero nem saber se naquele bar só entra homem, eu faço, mas eu tenho que fazer (Roma).
[...] já cheguei a comer lanche num lugar por causa do banheiro, que eles só dão à chave do banheiro se você gastar qualquer coisa [...], já cheguei a entrar em casa vazia pra poder ir ao banheiro [...] já entrei em casas Bahia várias vezes pra ir ao banheiro (Verona).

O manejo da IU é feito passo-a-passo envolvendo o reconhecimento do problema, ajustando as atividades e comportamentos para continuar a fazer o que faziam antes, ficando vigilantes e no controle. ${ }^{27} \mathrm{O}$ objetivo deste controle é evitar ou conter a urina usando estratégias fáceis, com pouca modificação no seu dia-a-dia e que podem ser incorporadas na rotina das suas atividades.

A questão do controle, nesta unidade temática, possibilita um feedback com a unidade - Sentimentos diante da perda, pois ao conseguir manter a perda sob-controle a mulher não se percebe estigmatizada e aos poucos retoma a confiança. Em adição, surge um efeito negativo, a mulher passa a pensar sempre na perda urinária, o que repercurte no seu estilo de vida, levando a problemas físicos, econômicos, psicológicos e sociais, que interferem no convívio social, familiar, sexual e profissional.

Assim, é possível reconhecer uma ambigüidade nas suas atitudes, pois ao mesmo tempo em que busca pelo controle, existe uma relutância em aceitar que essa ação levará a pensar constantemente no TER IU, portanto, a manutenção do controle da perda urinária será um pensamento contínuo.

[...] mas fica no subconsciente, exatamente, então vocêfica totalmente pensando naquilo. É eu sempre fico alerta (Roma).

Ah, é por que tá sempre ligada, sempre ligada, nunca tá desligada né. Tá sempre pensando (Verona).

Apesar de realizarem medidas para a contenção das perdas urinárias, a mulher possui a consciência que não é possível ter controle o tempo todo.

Às vezes vocêta num lugar que não tem como fazer xixi, você apertada é horrível. [...] você não consegue segurar e urina ali mesmo, eu já vi mulheres urinando assim, não agüenta segurar e urina (Milão).

\section{CONSIDERAÇÕES FINAIS}

A mulher quando estabelece uma relação com a incontinência urinária, concede outro significado à nova condição de vida. Nesta vivência ela tentará descobrir um processo para equilibrar o sentimento com a razão para possibilitar a compreensão do SER incontinente, identificando 
formas de enfrentamento para continuar a viver, apesar deste evento. Cada mulher, ao seu tempo, vive as unidades temáticas e direciona-se para o processo de repensar e manter a vida, apesar da incontinência urinária. Esse processo é representado pela junção da razão (TER) com o sentimento (SER) a compreensão de o seu próprio ser. Compreendemos que o convívio com IU tem um impacto negativo na vida dessas mulheres e acarreta repercussões no âmbito psicológico, físico, social, sexual, ocupacional e econômico. A relação que cada mulher estabelece com o TER incontinência urinária é única, pois o conviver com a perda urinária é justaposto com o SER incontinente.

Com esse trabalho espera-se que os profissionais da área da saúde observem as experiências de conviver com IU e levem em conta que são únicas para cada indivíduo. Os resultados permitiram compreender que o viver incontinente é uma condição heterogênea para cada mulher. A compreensão das suas narrativas foi fundamental para entender a experiência de viver e manejar a incontinência urinária, portanto isso possibilita a prestação de uma assistência de enfermagem englobando a unicidade do SER e TER.

As mulheres buscam o equilíbrio de maneira dinâmica, constante e reflexiva, direcionada para a resolução dos infortúnios provocados pela perda urinária. Nesse processo, elas buscam a superação das barreiras impostas em suas vidas e continuam a viver, apesar da incontinência urinária.

As narrativas das mulheres contribuíram para a identificação da relação dialógica entre o TER incontinência e o SER incontinente. Isso levou-nos a redescobrir a justaposição entre razão e sentimento, logo neste momento tornamo-nos inseparáveis e passíveis de sermos cuidados.

Existem desafios pela frente pois o conhecimento sobre os índices de prevalência nacional da IU necessitam ser ampliados. Os centros de referência para manutenção da continência e tratamento da incontinência são um número reduzido e estão localizados em grandes metrópoles. Além disso, outros fatores como: desconhecimento, atitudes negativas das mulheres, falta de conhecimento de parcela significativa dos profissionais de saúde e poucos programas de saúde voltados para a prevenção e tratamento da incontinência urinária contribuem para que não sejam evidenciados quantitativa e qualitativamente esses índices.

As descobertas da pesquisa se desdobraram em novas inquietações possibilitando visualizar caminhos, experiências e fatos para serem reve- lados. Outras metas estão sendo traçadas, culminando em um redirecionamento da assistência de enfermagem e em estudos relacionados ao cuidar das mulheres com incontinência urinária.

\section{REFERÊNCIAS}

1 Kelleher CJ, Cardozo LD, Khullar V, Salvatore S. A new questionnarie to asses the quality of life of urinary incontinence women. Br J Obstet Gynaecol. 1997 Dez; 104(12):1374-79.

2 Nitti VW. The prevalence of urinary incontinence. Rev Urol. 2001 Dez; 3(Supl 1):S2-6.

3 Abrams P, Cardoso L, Fall M, Griffiths D, Rosier P, Ulmsten $\mathrm{U}$, et al. The standardization of terminology of lower urinary tract function: report from the standardization sub-committee of the international continence society. Urology. 2003 Jan; 61(1):37-49.

4 Sykes D, Castro R, Pons ME, Hampel C, Hunskaar $S$, Papanicolaou $S$, et al. Caracteristics of female oupatients with urinary incontinence participating in a 6- month observational study in 14 European countries. Maturitas. 2005 Nov; 52(Supl 2):S13-23.

5 Harwardt T, Fuentes B, Venegas M, Leal C, Verdugo F, Bernier P. Estudio de prevalencia de incontinencia urinaria en mujeres de Isla de Pascua. Rev Chilena de Urologia. [periódico na Internet] 2004 [acesso em 2006 Out 06]; 69(1): [5 p.]. Disponível em: http:// www.urologosdechile.cl/pdf.php?id=21

6 Guarisi T, Neto AMP, Osis MJ, Pedro AO, Paiva LHC, Faúndes A. et al. Incontinência urinária entre mulheres climatéricas brasileiras: inquérito domiciliar. Rev Saúde Públ. 2001 Oct;35(5):428-35.

7 Higa R. Incontinência urinária: problema ocupacional entre profissionais de enfermagem.[tese]. Campinas (SP): Universidade Estadual de Campinas. Faculdade de Ciências Médicas; 2004.

8 Silva APM, Santos VLCG. Prevalência da incontinência urinária em adultos e idosos hospitalizados. Rev Esc Enferm USP [periódico na Internet]. 2005 Mar [acesso em 2006 Jan 13]; 39(1): [9 p.]. Disponível em: http:/ / www.eeusp.br/reeusp/ upload/pdf/43.pdf.

9 Simonetti R, Truzzi JC, Bruschini H, Glashan RQ, Lelis MAS. Incontinência urinária em idosos: impacto social e tratamento. A Terceira Idade. 2001 Nov; 12(23):53-69.

10 Mendonça M, Reis RV, Macedo CBMS, Barbosa KSRS. Prevalência da queixa de incontinência urinária de esforço em pacientes atendidas no serviço de ginecologia do Hospital Júlia Kubitschek. J Bras Ginecol. 1997 Mai; 107(5):153-5.

11 Portelli A. Tentando aprender um pouquinho: algumas reflexões sobre a ética na história oral. In: Perelmutter D, Antonacci MA. organizadores. Ética da história oral. Revista do Programa de Estudos Pós-Graduados em História e do Departamento de 
História da Pontifícia Universidade Católica (SP). 1997 Abr;15(15):13-50.

12 Thompson EP. A voz do passado: história oral. Rio de Janeiro (RJ): Paz e Terra, 1992.

13 Boff L. Ethos mundial: um consenso mínimo entre os humanos. Brasília (DF): Letra Viva, 2000.

14 Peyrat L, Haillot O, Bruyere F, Boutin JM, Bertrand $\mathrm{P}$, Lanson Y. Prevalence and risk factors of urinary incontinence in young and middle-aged women. BJU Int. 2002 Jan; 89(1):61-6.

15 Hunskaar S, Lose G, Sykes D, Voss S. The prevalence of urinary incontinence in women in four European countries. BJU International. 2004 Feb; 93(3):324-30.

16 Ferolla EC. A auto-estima de mulheres portadoras de incontinência urinária de esforço. [tese] São Paulo: Universidade de São Paulo. Escola de Enfermagem; 2001.

17 Reis RB, Cologna AJ, Martins ACP, Paschoalin EL, Tucci Jr S, Suaid HJ. Incontinência urinária no idoso. Acta Cir Bras. 2003; 18(Supl 5):47-51.

18 Espuña M, Puig M, Pérez A, Rebollo P. Incontinência de orina de esfuerzo: primeira causa de incontinência em las remetidas a una unidad de uroginecología. Arch Esp Urol. 2004 Jul-Ago; 56(6):633-40.

19 Canguilhem G. O normal e patológico. $5^{\mathrm{a}}$ ed. Rio de Janeiro (RJ): Florence Universitária; 2002.

20 Horrocks S, Somerset M, Stoddart H, Peters T. What prevents older people from seeking treatment for urinary incontinence? A qualitative exploration of barriers to the use of community continence services. Family Practive. 2004 Dec; 21(6):689-96.

21 Taille Y. O sentimento de vergonha e suas relações com a moralidade. Psicol Refl Crít. 2002 Jan; 15(1):13-25.

22 Lopes MHBM, Higa R. Restrições causadas pela incontinência urinária à vida da mulher. Rev Esc Enferm USP. [periódico da Internet] 2006 Mar [acesso em 2006 Nov 20]; 40(1): Disponível em: http://www.eeusp.br/reeusp/upload/ pdf/215.pdf.

23 Zorn BH, Montgomery H, Pieper K, Gray M, steers WD. Urinary and depression. J Urol. 1999 Jul; 162(1):82-4.

24 Watson AJS, Currie I, Curran S, Jarvis GJ. A prospective study examining the association between the symptoms of anxiety and depression and severity of urinary incontinence. Eur J Obstet Gynecol. 2000 Jan; 88(1):7-9.

25 Nygaard I, Turvey C, Burns TL, Crischilles E, Wallace R. Urinary incontinence and depression in middle-aged United States women. Obstet Gynecol. 2003 Jan; 101(1):149-56.

26 Damião EBC. Sendo difícil não ter controle: a família vivenciando a doença crônica da criança. [tese] São Paulo (SP): Universidade de São Paulo. Escola de Enfermagem; 1997.

27 Bush TA, Castellucci DT, Phillips C. Exploring Women's beliefs regarding urinary incontinence. Urol Nurs. 2001 Jun; 21(3):211-18. 